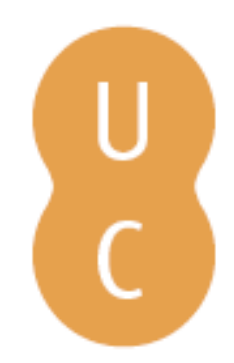

\title{
nombalina
}

\section{La criminalidad femenina ante la justicia episcopal en la Salamanca del siglo XVII}

Autor(es): $\quad$ Heras Santos, José Luis de las

Publicado por: Imprensa da Universidade de Coimbra

URL

persistente: URI:http://hdl.handle.net/10316.2/37191

DOI: $\quad$ DOI:http://dx.doi.org/10.14195/978-989-26-1033-7_4

Accessed : $\quad$ 26-Apr-2023 16:27:59

A navegação consulta e descarregamento dos títulos inseridos nas Bibliotecas Digitais UC Digitalis, UC Pombalina e UC Impactum, pressupõem a aceitação plena e sem reservas dos Termos e Condições de Uso destas Bibliotecas Digitais, disponíveis em https://digitalis.uc.pt/pt-pt/termos.

Conforme exposto nos referidos Termos e Condições de Uso, o descarregamento de títulos de acesso restrito requer uma licença válida de autorização devendo o utilizador aceder ao(s) documento(s) a partir de um endereço de IP da instituição detentora da supramencionada licença.

Ao utilizador é apenas permitido o descarregamento para uso pessoal, pelo que o emprego do(s) título(s) descarregado(s) para outro fim, designadamente comercial, carece de autorização do respetivo autor ou editor da obra.

Na medida em que todas as obras da UC Digitalis se encontram protegidas pelo Código do Direito de Autor e Direitos Conexos e demais legislação aplicável, toda a cópia, parcial ou total, deste documento, nos casos em que é legalmente admitida, deverá conter ou fazer-se acompanhar por este aviso. 
AS MULHERES PERANTE

OS TRIBUNAIS DO

ANTIGO REGIIME NA PENÍNSULA JBÉRICA

ISABEL M.R. MENDES DRUMOND BRAGA MARGARITA TORREMOCHA HERNÁNDEZ (COORDENAÇÃO)

IMPRENSA DA

UNIVERSIDADE

DE COIMBRA

COIMBRA

UNIVERSITY

PRESS 


\section{LA CRIMINALIDAD FEMENINA ANTE LA JUSTICIA EPISCOPAL EN LA SALAMANCA DEL SIGLO XVII*}

José Luis de las Heras Santos

Universidad de Salamanca

\section{Introducción}

La perspectiva de género fue introducida con gran provecho por Enrique Villalba en un análisis general sobre las causas criminales de la Sala de Alcaldes de Casa y Corte durante el Barroco. El trabajo de este autor dejó patente que la legislación ofrece una descripción estereotipada y deformada de la vida femenina, que gira en torno al matrimonio, y, sobre todo, en torno a los aspectos económicos del mismo. Este ensayo erradicó la idea de que la mayoría de las transgresiones de las mujeres estaban relacionadas con delitos contra la moral y especialmente con la prostitución. La realidad era que las mujeres del Madrid barroco eran capaces de ejecutar un repertorio amplio de delitos: podían robar, insultar, colaborar en estelionatos, amancebarse, quebrantar destierros o envenenar a sus maridos, porque muchas de ellas tenían una capacidad de iniciativa y llevaban vidas más activas de lo que a los moralistas de la época les hubiera gustado ${ }^{1}$.

\footnotetext{
${ }^{*}$ Este trabajo forma parte del pryecto de investigación Religionidad e Reforma Católica en el noroeste de la Península Ibérica durante el Antiguo Régimen (HAR2013-44187-P), financiado por el Ministerio de Economia y Competitividad.

${ }^{1}$ Enrique Villalba Pérez, ¿Pecadoras o delincuentes?: Delito y género en la Corte (15801630), Madrid, Calambur, 2004.
} 
Como ha indicado Ofelia Rey Castelao el modelo teórico de moralidad femenina de los tiempos modernos que insistía en la obligación de obediencia, humildad, modestia, discreción, vergüenza y retraimiento, no tuvo tanto éxito como en general se le atribuye ${ }^{2}$. En el caso gallego, que ella estudia, por la dificultad de reprimir comportamientos desviados en el medio rural y porque el clero de las aldeas frecuentemente incurría en los mismos pecados de incontinencia en los que caían sus feligreses.

En este estudio nos vamos a acercar a la realidad social de una ciudad castellana, muy marcada por el hecho de ser sede de una universidad en la que estudiaban miles de estudiantes y en la que el impacto de la iglesia era muy grande, tanto por el número de clérigos como por su influencia en la configuración de la mentalidad colectiva.

Partimos de la base de que en ninguna parte culminó completamente la ejecución del modelo teórico, y que en todos sitios hubo mujeres dispuestas a saltarse las rígidas normas de un orden jurídico en el que pecado y transgresión penal tendían a asimilarse. El caso salmantino es el de una diócesis en la que el disciplinamiento operado por la Reforma Católica tuvo éxito. Por tanto, un marco social muy distinto al de la Galicia rural.

Estamos de acuerdo con Tomás Mantecón cuando afirma que los procesos judiciales ofrecen una información estimable que permite cuantificar delitos, delincuentes, sentencias, etc., los cuales ofrecen una información estimable por sí misma; pero es necesario ir más allá y descubrir las significaciones de los fenómenos en sus contextos específicos, las transgresiones ocurridas, las actuaciones de las instituciones penales los logros disciplinares que obtienen ${ }^{3}$.

En el ámbito del País Vasco, Milagros Álvarez Urcelay ha estudiado la presencia de las mujeres dentro del mundo de la criminalidad de Bergara, una villa guipuzcoana del interior con una gran actividad económica y muy dinámica desde el punto de vista social durante la época preindus-

2 Ofelia Rey Castelao, "Las campesinas gallegas y el honor en la Edad Moderna", Las mujeres y el honor en la Europa Moderna, edición de $\mathrm{M}^{\mathrm{a}}$ Luisa Candau Chacón, Huelva, Publicaciones de la Universidad de Huelva, 2014, p. 431.

3 Tomás A. Mantecón Movellán, "Los impactos de la criminalidad en sociedades del Antiguo Régimen: España en sus contextos europeos", Vínculos de Historia, no 3, Ciudad Real, 2014, p. 56. 
trial. Dicha autora ha llegado a la conclusión de que el mundo vergarés de la delincuencia era esencialmente masculino, aunque es muy destacable la implicación de las mujeres en los delitos sexuales y los del apartado contra la familia. La explicación que se da de ello es que aunque, por ejemplo, en el delito de amancebamiento concurran dos personas, por tratarse de una acción cometida en pareja, la justicia ordinaria no encausa a muchos hombres por tratarse de clérigos a quiénes sólo los tribunales eclesiásticos podían juzgar. Desde nuestro punto de vista habría que seguir investigando para probar esta aseveración documentalmente, y demostrar definitivamente que los implicados son eclesiásticos y que no se trataba de una discriminación más de género, en virtud de la cual algunos delincuentes masculinos quedaban impunes por circunstancia que el juzgador estimó convenientes y que se deberían demostrar. Como peculiaridad de la delincuencia femenina vergaresa del siglo XVIII sobresale el alto porcentaje de mujeres implicadas en casos de contrabando, hasta el punto de que podría considerarse una actividad habitual de las mujeres para completar los ingresos familiares ${ }^{4}$.

Ramón Sánchez González ha estudiado 170 expedientes relativos a mujeres de las poblaciones de los Montes de Toledo, lo cual le ha permitido desvelar qué tipo de criminalidad femenina podemos encontrar en una zona rural como esa. Su conclusión es que en la inmensa mayoría de los casos, las mujeres aparecen implicadas en procesos en los que la sexualidad aparece como móvil determinante ${ }^{5}$.

A la vista de todo lo anterior puede deducirse que a día de hoy tenemos estudios representativos con los que comparar nuestras propias investigaciones sobre la criminalidad femenina. En esta ocasión hemos optado por centrar nuestras miradas en las actuaciones de la justicia eclesiástica, una jurisdicción que pese a su importancia no ha suscitado

${ }^{4}$ Milagros Álvarez Urcelay, "Mujeres y criminalidad en Guipúzcoa en el Antiguo Régimen: el caso de Bergara”, Marginación y Exclusión Social en el País Vasco, edición de Milagros Álvarez Urcelay, Iñaki Reguera Acedo, Iñaki Bazán Díaz, César González Mínguez, Bilbao, Universidad del País Vasco, 1999, pp. 246-250.

5 Ramón Sánchez González, Sexo y Violencia en los Montes de Toledo: Mujeres y Justicia durante la Edad Moderna, Toledo, Asociación para la Integración Laboral de la Mujer en Castilla-La Mancha, Asociación para el Desarrollo Integral del Territorio 'Montes Toledanos', 2006, p. 114. 
la atención de la investigación histórica en la misma medida que lo han hecho otras jurisdicciones, igualmente importantes, como la Inquisición.

Para comparar los datos de Salamanca disponemos del sólido trabajo realizado como tesis doctoral por Isabel Pérez Muñoz ${ }^{6}$ que ha examinado 321 procesos instruidos por la justicia episcopal de la diócesis de Coria a lo largo de los siglos XVI y XVII. El archivo diocesano de Salamanca es una institución bien atendida que alberga una documentación abundante y bien catalogada. Pertenecientes al siglo XVII se conservan 674 procesos criminales. 644 en los que los acusados son hombres, 20 en los que las acusadas son mujeres y 10 en los que hay hombres y mujeres como acusados.

\begin{tabular}{|c|c|}
\hline $\begin{array}{c}\text { Distribución por Sexos de los Procesos Criminales de la Jurisdicción Episcopal de } \\
\text { Salamanca en el siglo XVII }\end{array}$ \\
\hline $\begin{array}{c}\text { Procesos en los que los acusados son } \\
\text { HOMBRES }\end{array}$ & 644 \\
\hline $\begin{array}{c}\text { Procesos en los que las acusadas son } \\
\text { MUJERES }\end{array}$ & 20 \\
\hline $\begin{array}{c}\text { Procesos en los que se acusa conjuntamente a } \\
\text { HOMBRES y MUJERES }\end{array}$ & 10 \\
\hline Total & 674 \\
\hline
\end{tabular}

\section{Rasgos generales de la delincuencia femenina castigada por la Justicia Episcopal}

Dentro de cada diócesis el obispo ostentaba la mayor autoridad eclesiástica, lo que se manifestaba en el ejercicio de tres poderes: orden, magisterio y jurisdicción. En virtud de su potestad jurisdiccional el obispo podía dar normas y estatutos sobre múltiples asuntos relacionados con el Derecho Canónico y el gobierno de su diócesis. De ello se derivaba la facultad de la justicia episcopal para intervenir sobre dichos asuntos, dictando sentencias y castigando culpables con penas espirituales y temporales según la gravedad de las faltas cometidas ${ }^{7}$. El obispo podía administrar

6 Isabel Pérez Muñoz, Pecar, Delinquir y Castigar: El Tribunal Eclesiástico de Coria en los siglos XVI y XVII, Cáceres. Institución Cultural 'El Brocense', 1992.

7 Un ejemplo típico de cómo se combinaban penas espirituales y materiales en la misma sentencia lo tenemos en el caso de Ana Vásquez, sardinera y mujer de un cabes- 
justicia por sí mismo, pero lo más común es que lo hiciera a través de su vicario o de otros jueces designados por él, en quienes delegaba su poder jurisdiccional. A sus tribunales llegaban las causas contenidas en la legislación episcopal en primera instancia o en apelación, y las sentencias dictadas eran recurribles ante el tribunal metropolitano o pontificio ${ }^{8}$.

El poder jurisdiccional de los obispos tenía un triple carácter: legislativo, judicial y ejecutivo y se aplicaba a todos los comportamientos que transgredían los principios morales y doctrinales de la iglesia. El deber de un obispo consistía en mantener el orden social y castigar a los clérigos y fieles sometidos a su jurisdicción, cuya conducta no se adecuase a las leyes divinas y eclesiásticas. El problema básico al que se enfrentaba la justicia episcopal era el de la diferenciación entre fuero interno, perteneciente al ámbito de la conciencia y el externo, referido a lo que era conocido públicamente. Mientras que las faltas cometidas en el fuero interno debían ser declaradas al confesor para que impusiese una penitencia, los tribunales eclesiásticos sólo tenían competencia en aquello que se conocía públicamente, y que por tanto formaba parte del fuero externo. El procedimiento judicial canónico prefería el testimonio oral a la prueba escrita, y de ahí la importancia que tenían los testigos en los juicios.

Juan Hernández Franco y Encarnación Meriñán Soriano han estudiado las relaciones sexuales extramatrimoniales en el período inmediatamente posterior al concilio de Trento en la zona de Lorca, utilizando como

trero de Salamanca, a quien el fiscal episcopal acusó "porque con poco temor de Dios y menosprecio de la justicia es mujer supersticiosa y hechicera y hace cercos y habla con el demonio y hace conjuros y dice palabras secretas y debajo de algunas palabras que dice buenas, las mezcla con otras malsonantes de invocación al demonio y esto tiene por uso y lleva dineros por ello y embuste a muchas personas, de lo cual hay mucho escándalo y murmuración y ha cometido graves y atroces delitos dignos de punición".

En atención a estos hechos fue condenada "en que ayune nueve viernes y en cada uno de ellos rece el rosario a nuestra señora y haga decir en cada uno de los viernes una misa por las almas del purgatorio, la cual oiga y acabada, bese la mano del sacerdote que la dijere en señal de obediencia a la Santa Madre Iglesia. Más la condenamos en año y medio de destierro de esta ciudad y sus arrabales. Los seis meses precisos y los demás voluntarios según fuere voluntad del juez". Salamanca, Archivo Diocesano de Salamanca (A.D.S.), Proceso Criminal contra Ana Vázquez, Audiencia Episcopal, leg. 43, nº 8.

8 Jorge Díaz Ibáñez, "La potestad jurisdiccional del obispo y cabildo burgalés durante el siglo XV", Medievalismo: Revista de la Sociedad Española de Estudios Medievales, ${ }^{\circ}{ }^{\circ} 2$, Madrid, 2012, pp. 77 y 78. 
fuente la documentación notarial. Su conclusión fue que a pesar de la teórica igualdad esencial de todos dentro de la creación armónica de la humanidad, se percibe una situación de subordinación, desigualdad e inferioridad de las mujeres en aquella sociedad de directrices, decisiones y actitudes homocéntricas.

En el período contrarreformista que se inició hacia 1560 la sexualidad fue objeto de una cuidada atención didáctica y represiva. El matrimonio se estableció como único marco de sexualidad. Se prohibieron las prácticas sexuales extramatrimoniales, pero continuó cierta sensualidad incontrolada. Como consecuencia de estos actos la mujer no podía conservar lo que el rol cultural le imponía: la virginidad en el caso de la soltera y la exclusiva relación con el cónyuge en el caso de la casada. Además, junto con la virginidad, la mujer perdía el honor-virtud, que era su máximo capital simbólico?

Ya se sabe que la delincuencia perseguida por la justicia diocesana no era toda la perpetrada. En primer lugar, porque todos los tribunales son selectivos en sus actuaciones y en segundo lugar porque junto a la justicia eclesiástica existían otras jurisdicciones: real, señorial, universitaria, etc. En realidad nuestro estudio no versa tanto sobre la criminalidad existente en la diócesis, como sobre las actuaciones del juez eclesiástico.

En relación con la tipología de la delincuencia femenina castigada por la justicia episcopal en el siglo XVII, podemos adelantar que la represión de la alcahuetería fue un objetivo central. Del total de los 20 procesos en los que las mujeres fueron encausadas con carácter exclusivo, más de la mitad estaban relacionados con transgresiones sexuales. En nueve de ellos se las acusó de "alcahuetas y encubridoras", en dos de amancebamiento y en uno de poligamia.

Los demás procesos se reparten de la siguiente forma: dos de agresiones físicas, uno de hechicería, uno de robo, uno por desenterrar el cadáver de un recién nacido y tres procesos contra mujeres religiosas que serán comentados más adelante.

\footnotetext{
9 Juan Hernández Franco y Encarnación Meriñán Soriano, "Notas sobre sexualidad no permitida y honor en Lorca (1575-1615)," Historia de la mujer e historia del matrimonio, dirección de María Victoria López-Cordón Cortezo y Montserrat Carbonell i Esteller, Murcia, Universidad de Murcia, 1997, pp. 131-138.
} 


\begin{tabular}{|l|l|}
\hline Tipología de la Delincuencia Femenina Castigada por la Justicia Episcopal \\
\hline Procesos en los que se acusa a mujeres de alcahuetas y encubridoras & 9 \\
\hline Procesos en los que se acusa a mujeres de amancebamiento & 2 \\
\hline Procesos en los que se acusa a mujeres de agresiones físicas & 2 \\
\hline Procesos en los que se acusa a la mujer de poligamia & 1 \\
\hline Procesos en los que se acusa a la mujer de hechicería & 1 \\
\hline Procesos en los que se acusa a la mujer de robo & 1 \\
\hline Procesos en los que se acusa a la mujer de desenterrar un recién nacido & 1 \\
\hline Procesos en los que se acusa a mujeres religiosas & 3 \\
\hline Total Procesos & 20 \\
\hline
\end{tabular}

En cuanto a los delitos en los que intervinieron hombres y mujeres conjuntamente, todos están relacionados con materia sexual. En 10 procesos fueron acusados hombres y mujeres en la misma causa. En nueve de estos procesos los implicados fueron acusados de amancebamiento y en un caso de adulterio.

Tras saber de qué se les acusaba a las mujeres conviene averiguar quién las acusa. La tónica general es que los procesos criminales contra las mujeres son incoados de oficio por la justicia eclesiástica, sin acusación de parte. Tanto los procesos en los que las mujeres aparecen como únicas denunciadas, como aquellos otros en los que comparten acusación y delito con algún hombre, se instruyeron por iniciativa propia de la justicia episcopal. La única excepción es, por otra parte, una mujer casada de las Casas del Conde que fue acusada de adulterio por su marido ${ }^{10}$.

Interesa conocer en qué poblaciones vivían las mujeres procesadas, porque ello nos permitirá saber el grado de desarrollo y de eficiencia de la justicia episcopal fuera de su sede capital. En la tabla adjunta se pueden ver los lugares de residencia de las personas acusadas, el número de procesos relativos a cada una de las poblaciones y la cantidad de habitantes en el censo de población de Floridablanca de $1787^{11}$.

10 Salamanca, A.D.S., Audiencia Episcopal. Proceso contra Catalina Hernández y Pedro de Ine. Año 1636. leg. 37, $\mathrm{n}^{\circ} 185$.

11 Utilizamos el censo de Floridablanca porque tenemos sus datos vaciados para toda la antigua provincia de Salamanca para un trabajo que estamos realizando sobre población y jurisdicciones en el siglo XVIII. Es verdad que dicho censo es más tardío, pero a los efectos de hacernos una idea del tamaño de las poblaciones, puede ser válido. Fuente: Miguel Artola, España Dividida en Provincias e Intendencias y Subdividida en Partidos, Corregimientos, Alcaldías Mayores, Gobiernos Políticos y Militares, así Realengos como de 


\begin{tabular}{|c|c|c|}
\hline Población & $\mathrm{N}^{\circ}$ de procesos & Habitantes 1787 \\
\hline Aladeadávila & 1 & 1511 \\
\hline Aldeatejada & 1 & 167 \\
\hline Cereceda & 1 & 284 \\
\hline Ciudad Rodrigo & 1 & 5254 \\
\hline La Vellés & 1 & 738 \\
\hline Las Casas del Conde & 1 & 566 \\
\hline Ledesma & 1 & 1844 \\
\hline Moriscos & 1 & 236 \\
\hline Pedrosillo de Salvatierra & 1 & 415 \\
\hline Salamanca & 10 & 16.267 \\
\hline Vecinos & 1 & 227 \\
\hline Vitigudino & 1 & 864 \\
\hline Villaverde & 1 & 346 \\
\hline Villoruela & 1 & 702 \\
\hline Zorita de la Frontera & 1 & 416 \\
\hline
\end{tabular}

Dicha tabla prueba que las mujeres procesadas vivían en muy diferentes poblaciones de la diócesis, de diferentes tamaños y a cualquier distancia de la capital, aunque se aprecia que faltan los lugares muy pequeños, que eran muy abundantes en la antigua provincia de Salamanca. El pueblo más pequeño en el que hubo alguna mujer procesada era Aldealengua, que tenía 167 habitantes, pero debemos indicar que en el censo de Floridablanca aparecen 516 núcleos de población con menos de 167 habitantes, en cuyo conjunto vivían 23.586 habitantes ${ }^{12}$. A partir de este dato hemos de pensar que las infracciones cometidas en los núcleos más pequeños eran corregidas por la propia comunidad por otros procedimientos.

Eventualmente encontramos a las mujeres como denunciantes, pero en la mayoría de los procesos incoados por denuncia de la mujer no se dictó

Órdenes, Abadengo y Señorío. Obra Formada por las Relaciones Originales de los Respectivos Intendentes, Madrid, Boletín Oficial del Estado, 2001.

12 En 1787 la provincia de Salamanca tenía 1067 núcleos de población con una densidad por debajo de la media de la Corona de Castilla. Se trataba, pues, de una provincia con una demografía débil y en la que abundaban los despoblados. 
sentencia y en el único caso que se dictó fue benigna, sin contar que finalmente se levantó la pena por orden del obispo sin explicar las razones.

Las mujeres aparecen como denunciantes en cinco casos. Cuando la mujer denuncia es porque ha sido víctima de agresiones, injurias y amenazas graves. Los agresores procesados son eclesiásticos que además son parientes en grado próximo con las víctimas. Los agresores justifican sus acciones porque dicen salir en defensa de otras mujeres de la familia - por ejemplo la madre del inculpado-, porque le habían reclamado una deuda indebidamente, porque la víctima sembraba discordias entre su hija y su yerno, porque había aconsejado a una mujer casada que no tuviese relación escandalosa con el clérigo agresor o porque tenía la sospecha de que la víctima - parienta suya - estaba amancebada ${ }^{13}$.

Son agresiones terribles: "Con mucha furia dio a la dicha Isabel Rodríguez una gran bofetada en el rostro, de la cual la bañó en sangre y le salió mucha sangre de la boca. Y no contento con esto la dio dos coces que la echó en el suelo y estando echada en él la dio dos o tres puñadas que a no llegar este testigo y quitársela a tiempo, la matara"14.

Los insultos contra las mujeres que aparecen en la documentación son los habituales de la época: bellaca, embustera, desvergonzada, loca, puta, alcahueta, pícara, etc. Las amenazas son siempre de muerte proferidas en momentos de gran enojo y exasperación.

13 Salamanca, A.D.S., Audiencia Episcopal: Proceso criminal de Isabel Gómez, vecina de Salamanca contra Pedro Sánchez de Segura, cura de la iglesia de San Marcos, por allanamiento de morada y agresiones (Año 1617, leg. 18, $\mathrm{n}^{\circ} 16$ ); Proceso criminal del fiscal de la Audiencia Episcopal de Salamanca contra Esteban López, beneficiado del lugar de Monleras, por atacar de palabra y obra a Isabel Rodríguez, mujer de Juan Recio, vecinos de Ledesma (Año 1631, leg. 32, $\mathrm{n}^{\circ}$ 172); Proceso criminal de Catalina Álvarez, vecina de Salamanca, contra el clérigo Juan Álvarez Mostaza, presbítero, acusándole de golpes y heridas cuando fue a pedirle lo que le debía de sus servicios como ama (Año 1634, leg. 35, n ${ }^{\circ}$ 72); Proceso criminal de Francisca Díez, viuda de Domingo Sánchez, vecina de Alba de Tormes, contra el clérigo José Rodríguez, cura del lugar de Sieteiglesias, por escándalo público y amenazas de muerte (Año 1641, leg. 42, nº 35); Proceso criminal de $\mathrm{D}^{\mathrm{a}}$ María de Guillamar, vecina de Salamanca y señora de Canillas, contra el canónigo D. Antonio de Mercado, por insultarla e intentar matarla (Año 1652, leg. $\left.40, \mathrm{n}^{\circ} 95\right)$.

14 Salamanca, A.D.S., Proceso criminal del Fiscal de la Audiencia Episcopal de Salamanca, contra Esteban López, beneficiado del lugar de Monleras, por atacar de palabra y obra a Isabel Rodríguez, mujer de Juan Recio, vecinos de la villa de Ledesma (Año 1631, leg. 32, $\mathrm{n}^{\circ} 172$ ). 
En la mayoría de los casos en los que la mujer fue denunciante no se dictó sentencia. En tres casos se suspendieron las diligencias procesales contra los acusados en un momento determinado y no se llegó a pronunciar sentencia. En otro caso la víctima querellante se apartó del proceso y se suspendieron las actuaciones judiciales. Seguramente la intermediación de terceras personas puso de acuerdo a las partes en instancias extrajudiciales, como era tan común en las sociedades del Antiguo Régimen. En uno de los procesos consta que aunque se suspendieron las actuaciones y no se dictó sentencia se le exigió al acusado por parte de la justicia episcopal el pago de las costas procesales.

Sólo en un caso se dictó sentencia, aunque benigna: "Se declara a Isabel Rodríguez por mujer honrada y virtuosa y no caber en ella las palabras que Esteban López le dijo". Al acusado se le amonestó y se le mandó "que de aquí adelante no diga semejantes palabras". "Por su culpa se le condena en seis meses de suspensión del oficio de presbítero". Llamamos la atención sobre el hecho de que en la sentencia se pasa por alto sobre el tema de los brutales golpes propinados a esta pobre mujer, mientras que se pone mucho cuidado en la reparación de su honra para que no quepa duda a nadie de que se trataba de una mujer honrada en quien no cabían tales injurias. Finalmente el obispo levantó la pena al condenado "por justas causas que le movieron a ello", pero que nunca explicó ${ }^{15}$.

La alcahuetería fue el delito femenino que más preocupó a la justicia eclesiástica en los últimos años del siglo XVI y primeros años del siglo XVII. Era una actividad fundamentalmente urbana, casi todos los casos perseguidos ocurrieron en la ciudad de Salamanca, una urbe llena de eclesiásticos y de estudiantes ${ }^{16}$.

15 Salamanca, A.D.S., Audiencia Episcopal, Año 1631, leg. 32, nº 172.

16 Salamanca, A.D.S., Audiencia Episcopal, proceso criminal contra María Casada, leg. 46, $\mathrm{n}^{\circ}$ 9. Proceso criminal contra María de Paredes, leg. 65, $\mathrm{n}^{\circ}$ 14. Proceso criminal contra Francisca Barrena, alias "La Trecha", leg. 68, $\mathrm{n}^{\circ}$ 16. Proceso criminal contra Isabel Rodríguez, leg. 72, $\mathrm{n}^{\circ}$ 7. Proceso criminal contra Francisca de Valdenebro, leg. 71, $\mathrm{n}^{\circ} 4$ Proceso Criminal contra Isabel Hernández, leg. 1, no 51 . Proceso criminal contra Violante Gómez, leg. 2, $\mathrm{n}^{\circ}$ 68. Proceso Criminal contra Juana Perera, leg. 3, $\mathrm{n}^{\circ}$ 62. Proceso criminal contra Antonia Núñez, leg. 5, n ${ }^{\circ} 19$. 
Los pleitos nos revelan quiénes eran los clientes de la alcahueta: estudiantes, religiosos de órdenes regulares, jóvenes solteros y hombres casados con relaciones extramatrimoniales más o menos habituales.

El modus operandi nos lo describen perfectamente las acusaciones del fiscal de la audiencia episcopal ${ }^{17}$ :

El licenciado Francisco de Segura, fiscal de la jurisdicción episcopal de Salamanca, dice que la acusada con poco temor de Dios y menosprecio de su justicia es pública alcahueta de hombres y mujeres de todos los estados para que se conozcan carnalmente y ofendan a Dios, dándoles casa y cama para ello, viviendo dos o tres mujeres de mal vivir en su casa para que los hombres que entran en su casa, las conozcan carnalmente. Y en particular ha alcahueteado y encubierto a María de Plasencia y a María Aguilar para que tuviesen acceso con sus amigos estudiantes. También ha permitido que una mujer casada tuviese relación con un estudiante. Por ello recibe dinero, comida y otros regalos ${ }^{18}$.

A la pregunta de quiénes son las alcahuetas, deberíamos responder que generalmente son mujeres pobres y solas. Así nos lo indica algún testimonio tipo: "No sabe si lleva dineros por estos tratos, pero sabe que la acusada no tiene hacienda de la que pueda sustentarse y supone que se lo pagarán ${ }^{19}$. La deposición anterior recuerda el caso de La Celestina:

¿Qué pensabas, Sempronio? ¿Habíame de mantener del viento? ¿Heredé otra herencia? ¿Tengo casa o viña? ¿Conósceme otra hacienda, más de este oficio? ¿De qué como y bebo? ¿De qué visto y calzo? ¿En

17 El modus operandi de las alcahuetas vizcaínas está bien descrito en José Patricio Aldama Gamboa, "Alcahuetas y prostitutas en Bilbao y su entorno en la Edad Moderna", Marginación y Exclusión Social en el País Vasco, edición de César González Mínguez, Iñaki Bazán Díaz e Iñaki Reguera, Bilbao, 1999, pp. 81-109.

18 Proceso criminal del fiscal de la Audiencia Episcopal de Salamanca contra Isabel Rodríguez, vecina de Salamanca y que vive en el Desfiladero, acusada de alcahueta y encubridora. Salamanca, A.D.S., Audiencia Episcopal, Año 1592, leg. 72, $n^{\circ} 7$.

19 Proceso criminal del fiscal de la Audiencia Episcopal de Salamanca contra Isabel Rodríguez. Testimonio de Miguel Méndez. Salamanca, A.D.S., Audiencia Episcopal, Año 1592, leg. $72, \mathrm{n}^{\circ} 7$ 
Los pleitos nos revelan quiénes eran los clientes de la alcahueta: estudiantes, religiosos de órdenes regulares, jóvenes solteros y hombres casados con relaciones extramatrimoniales más o menos habituales.

El modus operandi nos lo describen perfectamente las acusaciones del fiscal de la audiencia episcopal ${ }^{17}$ :

El licenciado Francisco de Segura, fiscal de la jurisdicción episcopal de Salamanca, dice que la acusada con poco temor de Dios y menosprecio de su justicia es pública alcahueta de hombres y mujeres de todos los estados para que se conozcan carnalmente y ofendan a Dios, dándoles casa y cama para ello, viviendo dos o tres mujeres de mal vivir en su casa para que los hombres que entran en su casa, las conozcan carnalmente. Y en particular ha alcahueteado y encubierto a María de Plasencia y a María Aguilar para que tuviesen acceso con sus amigos estudiantes. También ha permitido que una mujer casada tuviese relación con un estudiante. Por ello recibe dinero, comida y otros regalos ${ }^{18}$.

A la pregunta de quiénes son las alcahuetas, deberíamos responder que generalmente son mujeres pobres y solas. Así nos lo indica algún testimonio tipo: "No sabe si lleva dineros por estos tratos, pero sabe que la acusada no tiene hacienda de la que pueda sustentarse y supone que se lo pagarán ${ }^{19}$. La deposición anterior recuerda el caso de La Celestina:

¿Qué pensabas, Sempronio? ¿Habíame de mantener del viento? ¿Heredé otra herencia? ¿Tengo casa o viña? ¿Conósceme otra hacienda, más de este oficio? ¿De qué como y bebo? ¿De qué visto y calzo? ¿En

17 El modus operandi de las alcahuetas vizcaínas está bien descrito en José Patricio Aldama Gamboa, "Alcahuetas y prostitutas en Bilbao y su entorno en la Edad Moderna", Marginación y Exclusión Social en el País Vasco, edición de César González Mínguez, Iñaki Bazán Díaz e Iñaki Reguera, Bilbao, 1999, pp. 81-109.

18 Proceso criminal del fiscal de la Audiencia Episcopal de Salamanca contra Isabel Rodríguez, vecina de Salamanca y que vive en el Desfiladero, acusada de alcahueta y encubridora. Salamanca, A.D.S., Audiencia Episcopal, Año 1592, leg. 72, $n^{\circ} 7$.

19 Proceso criminal del fiscal de la Audiencia Episcopal de Salamanca contra Isabel Rodríguez. Testimonio de Miguel Méndez. Salamanca, A.D.S., Audiencia Episcopal, Año 1592, leg. $72, \mathrm{n}^{\circ} 7$ 
esta ciudad nacida y en ella criada, manteniendo honra, como todo el mundo sabe? Conoscida como soy. Quien no supiere mi nombre y mi casa tenle por extranjero 20 .

Los oficios "tapadera" de la alcahueta eran los oficios típicamente femeninos: costurera, partera, etc.

La relación entre alcahuetas y prostitutas es descrita fielmente por Magdalena de San Jerónimo, la mujer que promovió un sistema carcelario específico para las mujeres en la Edad Moderna:

Hay mujeres que toman una casita de por sí, con oficio de costureras, parteras u otros oficios semejantes y debajo de este color su casa es una tienda de ofensas a Dios, pecando unas veces por sus personas y otras acogiendo mujeres para lo mismo ${ }^{21}$.

Hay otras muchas que sirven de alcahuetas y de terceras, que, demás de hacer en su casa muchos malos recaudos, entran en muchas casas, y aún principales, haciendo gran estrago no sólo en las criadas, pero aún en las hijas y aún en las señoras, con grande ofensa de Dios, deshonra de una familia y escándalo de todo el pueblo.

Hase visto por experiencia que hay muchas mujeres de edad mayor que tienen por granjería tener dos o tres mujeres que con título de pedir limosna van a muchas partes a donde hacen muchas ofensas a Dios.

La reincidencia no era muy característica de la delincuencia de la época, pero en el caso de la alcahuetería perseguida por la justicia eclesial de Salamanca hemos hallado un $20 \%$ de recaidas en las mismas conductas. No se volvía a reincidir en la misma ciudad, pero bastaba un traslado desde Zamora o desde Valladolid a Salamanca para seguir ejerciendo la misma actividad con la esperanza de no ser detectada por las autoridades de la ciudad de acogida.

20 Francisco de Rojas, La Celestina o Tragi-comedia de Calisto y Melibea, Madrid, Imprenta de C. León Amarita, 1835, p. 72.

21 Isabel Barbeito, Cárceles y Mujeres en el siglo XVII. Razón y forma de la Galera, proceso inquisitorial de San Plácido, Madrid, Castalia. Instituto de la Mujer, 1991, p. 74. 
En una sociedad en la que la separación de sexos era muy estricta. La relación entre hombres y mujeres era complicada. Por más que se buscaran encuentros aparentemente casuales en los espacios en los que la sociabilidad de los jóvenes parecía más natural (las fiestas, las fuentes, los paseos, etc.), había una gran necesidad de colaboración de terceras personas (las amistades, los familiares, el personal de servicio, etc.). Cuando esa intermediación la efectuaban personas que lo tenían por oficio y su intervención se encaminaba fundamentalmente a facilitar las relaciones sexuales pecaminosas, estamos ante la figura de la celestina, personaje magistralmente retratado por Fernando de Rojas a finales del siglo XV y celebrado por todos los públicos de la Edad Moderna hasta su prohibición en 1792. El personaje existió en la realidad antes que en la literatura y a lo largo de toda la Edad Moderna hubo mujeres que por necesidad o ambición asumieron ese rol en cada una de las ciudades, arriesgándose a ser acreedoras de los correctivos sancionadores de los jueces de las distintas jurisdicciones.

La mentalidad mágica imperante en la época propició la utilización de la hechicería como un remedio para conseguir amores imposibles. Nunca sabremos hasta qué punto la hechicera creía en la eficacia de su magia. Con embustes, engaños y burlas se podía obtener ganancia fácil de corazones encandilados por la pasión erótico-amorosa. Independientemente de que se pudiese dudar de la capacidad de una bruja concreta para obrar hechizos, el hecho es que todo el mundo creía en la existencia de fuerzas sobrenaturales que podían actuar, si eran invocadas convenientemente. Otra cosa es que la brujería estuviese implacablemente perseguida por los poderes civiles y eclesiásticos por ser contraria a la cosmovisión cristiana establecida como verdad universal.

En este contexto podemos entender que fuera frecuente la asociación entre alcahuetería y embrujos. En cuatro pleitos la justicia episcopal formula cargos conjuntos de alcahuetería y hechicería con fines amorosos:

Que tienen por trato y oficio ser hechiceras y para este efecto buscan cosas malas como un perro y un gato negro y un sapo y un cordero para hacer bebedizos para dar a personas que quieran bien. 
Mataron un gato negro, un perro y un corderito, y colgaron un sapo y lo que echaba por la boca lo habían echado en un vaso, y allí habían echado sangre de los males de la mujer y que por estar preñada no la tenía, y se la sacó de las narices; y también habían de echar sangre de gato, perro y cordero, todos en un vaso y que con unas palabras que había de decir se lo había de echar en lo que bebiese el dicho Álvaro Gil. Por eso fueron al ama del dicho Álvaro Gil para que se lo diese. Y que una hierba que habían menester por no haber en esta ciudad, habían ido su madre y María Morcilla camino de Zamora a por ella, la cual habían molido y echado a la puerta del dicho Álvaro Gil ${ }^{22}$.

El caso más llamativo es el de una viuda que cortó un trozo de altar de una iglesia y lo molió para darle un bebedizo al licenciado Juan García, cuyos amores parecían inalcanzables por aquellos días:

El fiscal acusa grave y criminalmente a Antonia González y María Castaña, porque con poco temor de Dios y de la justicia se atrevieron a profanar en vana observancia de superstición y hechicería cometiendo graves y exorbitantes excesos en su profanación para conservar en sus ilícitos y detestables tratos a Juan García. Intentó darle por medio de un ama un pedazo de ara molida que por otro medio no podía acercarle de su desacertada comunicación, sin reparar y menos reconocer se le podía seguir su muerte o perder el juicio ${ }^{23}$.

Otra aplicación clásica de la hechicería tocaba a la cura de enfermedades. Isabel Rodríguez fue acusada en un pequeño lugar de la comarca de Vitigudino por hacer brebajes y conjuros para curar enfermedades.

22 Proceso criminal contra Antonia González, su madre (María González) y María Morcilla, acusadas de hacer bebedizos y ser hechiceras y a María González, además de alcahueta y encubridora. Testimonio de María de Paz. Salamanca, A.D.S., Audiencia Episcopal, Año 1609. leg. 10, $\mathrm{n}^{\circ} 49$.

23 Proceso criminal contra María Rodríguez, viuda, vecina de Ciudad Rodrigo, por dar unos polvos de "piedra de ara" a Antonia González Lobera, para dárselos al licenciado Juan García para que la quisiera. Acusación fiscal. Salamanca, A.D.S., Audiencia Episcopal, Año 1660, leg. 61, no 126. 
Fue amonestada por sentencia y "usando de benignidad se la condenó en 600 mrs.", al tiempo que se la mandó que "en lo sucesivo no curase con medicinas ni diciendo palabras ningunas sin que se entiendan y sólo pueda decir oraciones de la doctrina cristiana, so pena de excomunión y seis años de destierro" 24 .

En relación con las religiosas procesadas no hemos encontrado casos de transgresiones graves del celibato, que estarían muy justificadas por la falta de vocación de muchas profesas, a las cuales habían llevado al convento sin contar con su voluntad.

Es posible que la falta de vocación estuviese detrás del caso de María de Jesús que abandonó la clausura de su convento para irse a vivir a Ledesma ${ }^{25}$. También debemos tener en cuenta que las transgresiones de las monjas eran castigadas directamente por sus superioras, sin intervención episcopal. En atención a estas circunstancias consideramos que al obispado le preocupó sobre todo que las monjas actuaran de manera autónoma. Por ejemplo, que en su capilla expusieran la sagrada eucaristía sin estar expresamente autorizadas o que se distrajeran con la representación de una comedia en su capilla ${ }^{26}$.

Todas las mujeres estaban sometidas a algún hombre: al padre, al marido, a los hermanos. En el caso de las monjas eran guiadas por un padre espiritual y se comprueba que eventualmente podían ser corregidas por la justicia episcopal.

El honor era un factor decisivo en las relaciones interpersonales de la Edad Moderna, que afectaba al imaginario colectivo y a la moral. En el caso de las mujeres se ligaba estrechamente con su conducta

\footnotetext{
24 Proceso criminal contra Isabel Rodríguez "La Miguela", mujer de Nicolás de la Plaza y vecina del lugar de Cipérez. Salamanca, A.D.S., Audiencia Episcopal, Año 1625. leg. 19, n 190.

25 Proceso criminal contra María de Jesús, religiosa profesa, en el convento de Santa Isabel de Salamanca, por haber quebrantado la clausura e irse a Ledesma. Salamanca, A.D.S., Audiencia Episcopal. Año 1643, leg. 44, n 162.

26 Proceso criminal contra la hermana Mayor y demás beatas, de la casa de beatas, llamada también de la Caridad, perteneciente a la parroquia de San Julián de Salamanca, por haber sido expuesto el santísimo Sacramento en dicha casa. Año 1628, leg. $29, n^{\circ} 53$. También proceso criminal contra la abadesa del Convento de San Salvador, extramuros de Ledesma, y ciertos vecinos de la villa, por representar una comedia no autorizada en la capilla de dicho lugar. Año 1637, leg. 38, $\mathrm{n}^{\circ} 112$.
} 
sexual, afectando a la opinión y pública fama que los demás tenían de ella. El menoscabo de la honra afectaba de forma determinante a la ejecución de sus proyectos personales de vida. Eso explica que una mujer hiciera las cosas más inverosímiles por preservar su honor.

Una vecina de Herguijuela de la Sierra desenterró a su hijo recién nacido al poco de haber sido inhumado en la iglesia de la localidad. Cuando la justicia episcopal procedió contra Catalina Pérez, que así se llamaba aquella mujer, declaró:

Que la razón que tuvo la acusada para sacar la criatura, fue por verse afligida por la nota que en ella ponían los parientes de su desposado, dudando si sería suya la criatura porque les habían dicho que tenía de largo media bara y que si era así, no podía ser de dicho desposado, respecto del tiempo en que tuvo acceso con ella. Y que para satisfacerles se arrojó a desenterrarla para mostrársela.

En la investigación se probó que la acusada estaba apalabrada de matrimonio con Lorenzo Pérez para casarse, el prometido le expuso algunas dudas, porque el "niño" no debería tener más de tres meses y algunas personas le habían dicho que tenía más de siete, "y que siendo de tanto tiempo no se quería casar con ella por no ser suyo". "Por cuya causa, movida por la defensa de su honor y no juzgando cometía delito en desenterrar dicho niño, fue a la dicha sepultura y le desenterró, el cual habiéndoselo enseñado al dicho Lorenzo Pérez y visto que tendría los tres meses, poco más o menos, quedó satisfecho. Después echó el niño en el osario de dicha iglesia, y habiéndose sabido por unos niños que estaba allí, lo sacó del osario y lo llevó a la iglesia y lo enterró en dicha sepultura, donde se hallará”27. Salió en libertad bajo fianza de un familiar del Santo Oficio que se comprometió con sus bienes muebles y raíces. Como otras muchas veces no se depositó dinero alguno, cesaron las actuaciones judiciales y seguramente la interesada contrajo matrimonio con su novio, tal y como deseaba.

27 Proceso criminal contra Catalina Pérez, viuda, vecina de Herguijuela de la Sierra, por haber desenterrado un niño. Salamanca, A.D.S., Audiencia Episcopal. Año 1688, leg. 89, nº 84. 
Los sucesos de riñas de mujeres sancionadas por la justicia diocesana salmantina en el siglo XVII fueron dos. En ambos casos el sitio de los incidentes fueron lugares sagrados. Águeda Rodríguez, vecina de Pedrosillo el Ralo, riñó y agredió a Catalina Rodríguez cuando estaba a punto de comenzar la misa dominical. El motivo de la riña era frecuente en la época y en otras ocasiones hemos visto implicados a hombres. La razón: "Se quiso sentar en el asiento donde otras veces se sienta la acusada. Delante de muchas personas le dio un bofetón con ánimo de injuriarla, que la derribó el tocado en el suelo y le dio muchos porrazos y la hizo otros malos tratos" 28 . Pocos días después de la denuncia consiguió el apartamiento de la parte ofendida, "porque buenas gentes se lo han pedido, y lo principal por amor de Dios y ser tiempo de Santa Cuaresma, se apartaba de dicha querella y remitía cualquier derecho, tanto civil como criminal". El problema es que en este asunto no sólo había una parte perjudicada, sino que también había que rendir cuentas por el escándalo causado por alterar el orden en un templo consagrado. La sentencia amonestó a Águeda para que en lo sucesivo no riñese con nadie en la iglesia y se la condenó en 600 mrs. y costas.

El segundo incidente ocurrió en la iglesia parroquial de Vecinos durante las amonestaciones previas al matrimonio de Isabel Guillén. Su tía, que era contraria a la boda que se preparaba, no pudo aguantar la rabia y explotó en un ataque de ira "diciendo muchas palabras feas, le dio muchas puñadas y luego la asió con ambas manos de la garganta y si no fuera porque la ayudó la mujer de Juan Holgado, lo pasara muy mal".

El fiscal entendió que la acusada había cometido grave sacrilegio y atroz delito. Fue condenada en 1.000 mrs. de pena y las costas. Lo peor para ella es que también fue condenada "a que el día de Nuestra Señora de agosto oiga la misa mayor en pie con una vela de cera encendida en las manos”29.

28 Proceso criminal del fiscal de la Audiencia Episcopal de Salamanca contra Águeda Rodríguez, vecina de Pedrosillo el Ralo, por haber tenido pendencia dentro de la iglesia con Catalina Rodríguez, vecina de dicho lugar. Salamanca, A.D.S., Año 1628, leg. 29 , n 75.

29 Proceso criminal contra $M^{a}$ Guillén, vecina de Vecinos, por insultar y pegar a Isabel Guillén cuando estaba oyendo misa en la iglesia de dicha villa. Salamanca, A.D.S., Audiencia Episcopal, Año 1640, leg. 41, $n^{\circ} 136$. 
La condenada entendió que permanecer de pie durante la misa del día de la Asunción podía dañar gravemente la honra familiar y solicitó su conmutación, a lo cual accedió el juez eclesiástico:

"Como el lugar es de pocos vecinos y los más de ellos enemigos míos y se puede temer mirarán las cosas con malicia y pondrán nota en su persona y en la de su linaje, aunque no la haya, pide y suplica la conmutación de dicha pena por otra. Particularmente, como tiene devoción a la imagen de nuestra señora, la cual no tiene un frontal decente en su altar, puede hacer uno a su costa hasta la cantidad de dinero que se le señale".

\section{El destierro la pena más frecuente}

En relación con las penas impuestas por la justicia episcopal en la Salamanca del siglo XVII, lo primero que debemos indicar es que no siempre hubo sentencia. En el 40\% de los casos no se llegó a dictar fallo alguno. Pero ello no debe interpretarse como signo de ineficacia o de descuido judicial.

A la justicia eclesiástica no le importa tanto la gravedad de la infracción cometida como asegurarse el cese del escándalo y el desafío a las santas normas. Por otra parte, no era infrecuente que en el transcurso del proceso judicial intercediese algún eclesiástico en favor de la acusada, asegurando y afianzando que nunca más iba a incurrir en semejante infracción. A veces figura en el mismo proceso que determinado eclesiástico afianzó con sus bienes muebles y raíces para garantizar la buena vida futura de la acusada y que por este motivo se suspendían las actuaciones. Eso sí, con la amenaza de continuarlas y agravar las penas si reincidía.

En otras publicaciones nos hemos ocupado de la severidad en el castigo de la justicia ordinaria ${ }^{30}$. Sin embargo, la punición de la justicia

${ }^{30}$ José Luis de las Heras Santos, "Ejemplaridad, paternalismo y utilitarismo en la justica de la España de los Habsburgo”, Estudios humanísticos. Historia, 2013, no. 12, León, pp. 185-213; José Luis de las Heras Santos, La justicia penal de los Austrias en la Corona de Castilla, Salamanca, Universidad de Salamanca, 1991. 
eclesiástica se caracteriza por el comedimiento y la templanza. La sesión XIII del Concilio de Trento insistió en recordar a los obispos que eran pastores y no verdugos:

Acuérdense los obispos y demás ordinarios que son pastores y no verdugos y que conviene que rijan a sus súbditos de tal forma, que no se enseñoreen de ellos, sino que los amen como a hijos y hermanos, y se esfuercen con exhortaciones y avisos de apartarlos del mal, para no verse en la precisión de castigarlos con penas justas si llegan a delinquir; y si ocurriese por la fragilidad humana llegaran éstos a delinquir en algo, debe observarse aquel precepto de apóstol de razonar con ellos, de rogarles encarecidamente, de reprenderlos con toda bondad y paciencia, pues en muchas ocasiones puede más, para los que hay que corregir, la benevolencia que el rigor, la exhortación que la amenaza, y es preferible el amor a la autoridad; mas si por la gravedad del delito es necesario el castigo, de la justicia con misericordia, y de la severidad con dulzura, para que sin asperezas se conserve la disciplina saludable y necesaria de los pueblos, y los que han sido corregidos se enmienden o, si éstos no quieren enmendarse, se aparten de los vicios los demás ante el saludable ejemplo del castigo de los otros 31 .

En la jurisdicción eclesiástica tenían carta de naturaleza las penas espirituales, particularmente tratándose del castigo de eclesiásticos díscolos, pero no hemos observado que fueran frecuentes en el castigo de las infracciones femeninas.

La pena más habitual fue el destierro. El periodo más prolongado de destierro se le impuso a la mujer que hizo polvo un trozo de altar con ánimo de fabricar una bebida con la que conquistar los amores de su hombre deseado, la cual fue castigada con diez años de extrañamiento, cuando lo más habitual es que las mujeres fueran condenadas a períodos

${ }^{31}$ Antonio Benlloch Poveda, "Jurisdicción eclesiástica en la Edad Moderna. El proceso" Instituciones de la España Moderna. Las Jurisdicciones, coordinado por Enrique Martínez Ruiz y Magdalena de Pazzis Pi Corrales, Madrid, Actas, 1996, pp. 128 y 129. 
comprendidos entre uno y cuatro años. En el caso de las reincidentes, además de ser desterradas, fueron sacadas a la vergüenza pública y azotadas.

Siempre que sus circunstancias económicas lo permitieron, se les impuso alguna pena pecuniaria, y, cuando se pudo, no se les dejaron de cobrar las costas judiciales.

A la vista de lo expuesto anteriormente podemos deducir que a diferencia de lo que ocurría en el ámbito civil, el destierro fue una pena frecuente en la justicia eclesiástica para castigar los comportamientos sexuales ilegítimos de las mujeres.

A finales del siglo XV el destierro era la pena por excelencia del sistema penal en la Corona de Castilla, pero a partir del siglo XVI la aplicación del destierro iniciará un proceso de decadencia, siendo sustituido por la pena de galeras. No obstante, en la jurisdicción eclesiástica siguió usándose con profusión. Tenía la ventaja de que evitaba la continuación del delito en casos como el amancebamiento.

Los destierros se ligaban a un espacio geográfico y a unos límites temporales. Como normal general el lugar de extrañamiento era la población y los alrededores del lugar del que fuera vecino el delincuente o donde hubiera perpetrado el delito. En los casos más graves se le expulsaba de todo el territorio de la diócesis.

El destierro tenía consecuencias sociales, morales y económicas para quienes lo padecían. Para gentes con recursos económicos el destierro les ocasionaba perjuicios morales y menoscabos en sus niveles de disfrute del poder, pero no les abocaba a la marginación socio-económica ${ }^{32}$.

A quienes dependían de su trabajo diario el destierro les arrojaba a la marginación, produciendo un efecto rebote. La comunidad se deshacía de las personas que alteraban el orden establecido, pero al expulsarlas se potenciaba la proliferación de una población marginal. Las personas que tenían familiares o amistades en otras partes, se dirigían hacia allí, pero cuando se carecía de estos lazos de solidaridad, no era fácil salir adelante.

32 Iñaki Bazán Díaz, "El destierro en el País Vasco (siglos XIV-XVI): la exclusión social a través del sistema penal", Marginación y Exclusión Social en el País Vasco, Coordinado por César González Mínguez, Iñaki Bazán Díaz e Iñaki Reguera, Bilbao, Universidad del País Vasco, 1999, pp. 25-54. 
Las mujeres se enfrentaban a un problema grave. Sirva el ejemplo de las amancebadas. Se habían amancebado porque no podían pagar una dote que las introdujera en el mercado matrimonial y una vez desterradas se las obligaba a andar vagabundeando y viviendo de la caridad.

El amancebamiento es cosa de dos personas, pero podía procesarse sólo a uno de los culpables, si el juez lo consideraba oportuno. Al provisor general del obispado le preocupaba particularmente la persistencia de las relaciones amorosas ilícitas que se mantenían estables a lo largo del tiempo, porque ello causaba enorme escándalo y porque a ojos de todos suponían un desafío para el sacramento del matrimonio y para el orden familiar establecido por el derecho civil, el derecho canónico y por las convenciones sociales de la época.

Sin embargo, la continuidad de la relación espuria se podía evitar procesando a una de las dos personas implicadas. Para llevar a cabo la elección de cuál de ellos, se tenían en cuenta factores sociales (la calidad de cada una de las partes), el estado (si uno de ellos era casado, lo cual unas veces podía ser un agravante, pero otras podía eximir del castigo para evitar el escándalo), factores de género (frecuentemente se echaba la culpa de la transgresión a las mujeres, porque se les suponía que tenían la obligación de rechazar cualquier solicitud masculina).

Tenemos registrados dos casos en los que se procesó únicamente a las mujeres. Uno fue el caso de Isabel Rodríguez, moza soltera, amancebada con el licenciado Morales, catedrático de la universidad ${ }^{33}$. El otro fue el caso de María Rodríguez, lavandera de paños, amancebada con Gaspar Pimentel, estudiante universitario portugués ${ }^{34}$.

Las soluciones de la justicia episcopal fueron las siguientes: En el primer caso la acusada demostró que hacía un mes que había cortado su relación con el catedrático al darse cuenta del escándalo que estaba causando. La sentencia fue benigna: $200 \mathrm{mrs}$. de pena, más las costas del proceso. En el segundo caso la acusada se presentó voluntariamente ante

\footnotetext{
33 Proceso criminal contra Isabel Rodríguez, por estar amancebada con el licenciado Morales. Salamanca, A.D.S., Audiencia Episcopal, Año 1591, leg. 70, $\mathrm{n}^{\circ} 6$.

34 Proceso criminal contra María Rodríguez, acusada de estar amancebada con Gaspar Pimentel, portugués y estudiante en Salamanca. Salamanca, A.D.S., Año 1591, leg. 69, nº 19.
} 
el provisor general de la diócesis y éste la mandó salir de la ciudad, cosa que hizo y con ello terminaron las actuaciones judiciales.

En ocasiones los maridos se marchaban lejos por motivos diferentes y no se volvía a saber de ellos. $\mathrm{M}^{\mathrm{a}}$ José de la Pascua, Isabel Testón y Rocío Sánchez Rubio estudiaron hace unos años el impacto de la ausencia y el abandono en el mundo femenino. Las mujeres abandonadas se convertían en verdaderas viudas de vivos 35 .

Magdalena Villalonga se casó con un tal Francisco Sánchez, frutero de profesión y apodado "El Tahón” porque tartamudeaba. Tras un año de matrimonio se enroló en una compañía en Zamora y se marchó a combatir a Flandes. Al cabo de un tiempo corrió por la ciudad el rumor de que unos villanos le habían matado en Flandes cuando se encontraba junto a otros soldados. Algún tiempo después Magdalena se casó con un carnicero y cuando éste murió se casó con un herrador portugués. Más tarde, cuando éste falleció se amancebó con un estudiante.

Consultados los libros parroquiales por orden judicial, no aparecieron inscritos algunos de los supuestos matrimonios. De hecho algunos testigos declaran en el proceso que al menos en un par de ocasiones el primer marido volvió a la ciudad y recibió dinero de la acusada para que se marchase, a fin de seguir haciendo vida maridable con la pareja a la que estaba vinculada en aquellos momentos. Desgraciadamente se interrumpieron las diligencias judiciales y nunca se dictó sentencia en este caso, con lo cual desconocemos la solución dada por la justicia episcopal a este caso de poliandria.

\section{Conclusiones}

La documentación generada por cada tribunal de justicia da fe de las actuaciones del mismo. Cada jurisdicción tenía cometidos específicos, a veces

35 María José de la Pascua Sánchez, "La cara oculta del sueño indiano: mujeres abandonadas en el Cádiz de la carrera de Indias, "Chronica Nova: Revista de Historia Moderna de la Universidad de Granada, 1993, $\mathrm{n}^{\circ}$ 21, pp. 441-468; Rocío Sánchez Rubio e Isabel Testón Núñez, "Mujeres abandonadas, mujeres olvidadas," Cuadernos de Historia Moderna, n. ${ }^{\circ}$ 19, Madrid, 1997, pp. 91-120. 
compartidos con otras, aunque el mismo tema podía ser visto de una manera diferente en cada una de ellas y por tanto ser castigado de manera distinta.

Los estudios que se habían realizado sobre la criminalidad femenina reprimida por la justicia civil habían puesto de manifiesto que las mujeres eran capaces de cometer una variedad de delitos mayor que la reflejada en las fuentes literarias.

El análisis de la documentación relativa a la Audiencia Episcopal de Salamanca pone de relieve el esfuerzo de la iglesia por reprimir la sexualidad extramatrimonial, concentrando su trabajo en la lucha contra la alcahuetería y los amancebamientos.

El control de la moral social se convirtió en un tema de capital importancia en la Europa católica postridentina. De alguna manera se convirtió a las mujeres en depositarias de la moral pública. De ahí que la iglesia pusiera tanto énfasis en su educación y control, pues consideraba que su conducta influía no sólo en su salvación personal, sino también en la salvación de los hombres. Por otra parte, lo que estaba en juego no era sólo la salvación de las almas, era también la salvaguarda del orden social establecido ${ }^{36}$.

Como ha indicado Ofelia Rey Castelao, el modelo teórico de moralidad femenina de los tiempos modernos no tuvo un éxito tan rotundo como a veces se le atribuye, pero qué duda cabe que la conjunción de actuaciones de tribunales tan distintos con el objetivo común de moralizar la vida social según los principios doctrinales de la iglesia católica, tuvo como consecuencia el disciplinamiento de la sociedad hasta cotas muy elevadas.

La iglesia sabía que la debilidad del ser humano le hacía caer en los pecados de la carne y para remedio de ello disponía del sacramento de la penitencia. A la luz de los procesos estudiados se deduce que a la justicia eclesiástica le preocupaba relativamente la represión de hechos pecaminosos concretos. A través de la confesión se imponía a cada fiel la penitencia individualizada por sus pecados. Sin embargo, las actuaciones judiciales se reservaban en buena medida para erradicar conductas

36 María Ruiz Ortiz, "Normas y resistencias femeninas: una mirada cotidiana a través de las sumas de confesión (ss. XVI-XVIII)", Las mujeres y el honor en la Europa Moderna, dirigido por María Luisa Candau Chacón, Huelva, Universidad de Huelva, 2014, pp. 165-187. 
escandalosas persistentes y continuas, que suponían un verdadero desafío para la moralidad vigente en la sociedad cristiana.

La inmensa mayoría de los procesos contra las mujeres son incoados de oficio por iniciativa del propio juez eclesiástico. La razón de ello es que en casi ninguno hay perjuicio de parte y por tanto no hay quien pretenda resarcirse del daño acudiendo al juez. Por otra parte, que no figuren denunciantes no quiere decir que no los hubiera. En la cabeza de muchos procesos se deja traslucir que antes de comenzar la instrucción de los mismos, el provisor conocía todos los pormenores y circunstancias de los casos. En realidad el proceso no iba encaminado a investigar una verdad que ya se conocía en sus aspectos fundamentales, sino que buscaba confirmarla y dejar constancia escrita de los testimonios recogidos conforme al derecho canónico. Quizás, la finalidad última del proceso era legitimar la condena. Creemos que a través de contactos privados y de la confesión, los párrocos conocían comportamientos aparentemente mantenidos en la intimidad, pero en realidad muy divulgados por la murmuración.

Ninguna mujer denunció criminalmente malos tratos del marido. Cuando las agresiones del esposo eran demasiado insoportables, se podía iniciar un proceso de divorcio que permitía disolver el vínculo matrimonial y recuperar la dote. Quienes aparecen como agresores de las mujeres en los procesos criminales de la justicia diocesana son eclesiásticos que además eran parientes suyos en grado próximo o tenían una relación muy cercana; por ejemplo, porque se trataba de su empleada doméstica. Ya hemos indicado más arriba hasta qué punto las mujeres estaban sometidas a los hombres, ahora debemos dejar constancia de la violencia con la que eran tratadas cuando cualquier individuo encolerizado de su familia tenía alguna diferencia con ellas. En estos casos las denuncias podían servir para amilanar un poco al agresor, pero casi nunca se llegaba a dictar sentencia y por tanto su conducta quedaba impune.

En una sociedad en la que existía una separación estricta de sexos, las relaciones entre hombres y mujeres resultaban difíciles. Por eso eran tan necesarias las intermediaciones y de ahí que la iglesia insistiera tanto el perseguir la alcahuetería, que además de facilitar relaciones sexuales 
inmorales, caía con frecuencia en el delito de hechicería como supuesto remedio para alcanzar amores irrealizables.

La justicia ordinaria recurría con frecuencia a un rigor exagerado en las condenas para resultar efectiva. Se complacía en el amedrentamiento ejemplificante. Sin embargo, la justicia episcopal demuestra una eficacia sorprendente con actuaciones bastante comedidas que consiguieron altos niveles de disciplinamiento social.

En la jurisdicción eclesiástica fueron características las penas espirituales. Junto a ellas, la pena de destierro fue la más frecuente y para las reincidentes se dejaron los azotes y la vergüenza pública. Al igual que en la justicia civil, las penas pecuniarias y el cobro de costas procesales fue esencial para sufragar los gastos del sistema judicial.

El destierro había sido la pena por excelencia en la Corona de Castilla hasta finales del siglo XV, pero a partir del siglo XVI el destierro fue cediendo terreno en el sistema penal castellano en favor de la pena de galeras. No obstante, en la jurisdicción eclesiástica siguió conservando una posición central, pues tenía la ventaja de evitar la continuidad del delito en casos como el amancebamiento. En contrapartida también podía tener efectos dañinos. Las mujeres desterradas que no se reinsertaban en otra población, porque no podían o porque no querían, empezaban a vagar de unas ciudades a otras, viviendo de la caridad pública o reincidiendo en las mismas transgresiones en otros lugares. 
Série Investigação

Imprensa da Universidade de Coimbra

Coimbra University Press

2015 